\title{
COMPUTER VISION PHOTOGRAMMETRY FOR UNDERWATER ARCHAEOLOGICAL SITE RECORDING IN A LOW-VISIBILITY ENVIRONMENT
}

\author{
T. Van Damme \\ Maritime Archaeology Programme (MAP), University of Southern Denmark, Esbjerg, Denmark \\ thomas.van.damme@outlook.com
}

Commission V

KEY WORDS: Computer Vision, Photogrammetry, Recording, Underwater Archaeology, Shipwrecks, Agisoft PhotoScan

\begin{abstract}
:
Computer Vision Photogrammetry allows archaeologists to accurately record underwater sites in three dimensions using simple twodimensional picture or video sequences, automatically processed in dedicated software. In this article, I share my experience in working with one such software package, namely PhotoScan, to record a Dutch shipwreck site. In order to demonstrate the method's reliability and flexibility, the site in question is reconstructed from simple GoPro footage, captured in low-visibility conditions. Based on the results of this case study, Computer Vision Photogrammetry compares very favourably to manual recording methods both in recording efficiency, and in the quality of the final results. In a final section, the significance of Computer Vision Photogrammetry is then assessed from a historical perspective, by placing the current research in the wider context of about half a century of successful use of Analytical and later Digital photogrammetry in the field of underwater archaeology. I conclude that while photogrammetry has been used in our discipline for several decades now, for various reasons the method was only ever used by a relatively small percentage of projects. This is likely to change in the near future since, compared to the 'traditional' photogrammetry approaches employed in the past, today Computer Vision Photogrammetry is easier to use, more reliable and more affordable than ever before, while at the same time producing more accurate and more detailed three-dimensional results.
\end{abstract}

\section{INTRODUCTION}

'Research and reconstruction are contributions; recording is a debt ... Once the site has been opened, once the sanctity of this public legacy has been entered, the select few who have intruded become indebted to the rest of us to tell precisely what they have observed. Recording is the most important step in the whole process.' (Steffy, 1994)

Whether working on land or underwater, archaeologists agree that recording is one of the most defining aspects of our discipline. It is only through the accurate recording of a site that we can justify the destructive process of excavation. Proper recording ensures the preservation of knowledge for future generations and forms the groundwork for any research that might follow. As such it is crucial that archaeologists strive to document each site to the best of their abilities; as accurately, completely and objectively as possible within the time, budget and environmental constraints imposed. On the one hand recording sites to the best of our abilities means making the most of established recording methods. On the other hand, it also entails reassessing these methods and exploring new, innovative and perhaps better ways of documenting our heritage.

Today, the bulk of underwater archaeological site recording is done using relatively elementary recording techniques such as scale drawings, offset measurements, tape measure trilateration and simple photography. These methods are robust enough to be used in the underwater environment, and they have the advantage that they are both affordable and reliable. On the other hand they are not very accurate, and - with the exception of photography - they are very time-consuming and prone to human errors. Furthermore, these recording techniques generally only produce either two-dimensional or greatly simplified three-dimensional representations of a site. As such they fail to capture all the complex three-dimensional details and relationships which are an integral part of most underwater sites, and which can be very important for site interpretation.

On the other end of the spectrum researchers can choose from a range of highly advanced, time-efficient, super accurate, threedimensional underwater recording techniques. However, the drawback of these high-tech methods is that they are generally too costly and/or too technical for the average archaeological project.

Fortunately, in recent years one recording method has emerged which promises to bridge the gap between these two extremes, providing highly accurate three-dimensional data of underwater sites, at a fraction of the cost of more advanced techniques. This method, which can be referred to as Computer Vision Photogrammetry, essentially allows users to upload a series of overlapping pictures of a scene or object into dedicated software in order to (semi-)automatically generate a 3D model of that scene or object. Having initially gathered pace in terrestrial heritage research, over the past few years Computer Vision Photogrammetry has also been increasingly used for underwater recording (Mahiddine et al., 2012; Mahon et al., 2011; McCarthy and Benjamin, 2014; Mertes et al., 2014; Skarlatos et al., 2012; Zhukovsky et al., 2013; to name but a few).

In this article I want to contribute to this growing body of research by sharing my experiences in working with one Computer Vision Photogrammetry software in particular, namely PhotoScan, to record and model a late $17^{\text {th }}-$ early $18^{\text {th }}$ century Dutch shipwreck. Based on this case study I will 
attempt to draw some conclusions regarding Computer Vision Photogrammetry's potential for recording underwater sites assessing the method's overall performance compared to manual recording methods, but also compared to the 'traditional' photogrammetry approaches used in underwater archaeology since the 1960s.

\section{AGISOFT PHOTOSCAN}

Advertised as 'an advanced image-based $3 D$ modelling solution aimed at creating professional quality $3 D$ content from still images' (Agisoft LLC, 2014), PhotoScan was originally released mid-2010 by the software company Agisoft LLC, based in St. Petersburg.

The software is available in two editions: a Standard edition targeted at hobby users, and a Professional edition targeted at survey professionals and the digital animation industry. While both editions contain all the essential features required to generate an accurate 3D model from images, the Professional edition offers additional functionality such as model scaling, marker-based chunk or picture alignment and geo-referencing of models.

A normal stand-alone license of PhotoScan costs $\$ 179$ for the Standard edition and $\$ 3499$ for the Professional edition. However, educational institutions and their affiliates get a sharp discount, given they don't use the product for commercial purposes: Educational licenses cost just $\$ 59$ for the Standard edition and \$549 for the Professional edition. Anyone wishing to try the software for the first time can also download a free 30-day trial of PhotoScan which offers the same functionality as the Professional edition.

PhotoScan converts images into textured 3D models in four straightforward processing steps, namely 1) Align Photos, 2) Build Dense Cloud, 3) Build Mesh and 4) Build Texture. For each of these steps different processing settings can be chosen in order to fine-tune the processing procedure to the needs of the specific image sequence. Additionally, between each major processing step the user has the opportunity to perform additional smaller actions in order to improve the final results. These actions include picture masking, deleting erroneous points, importing camera positions from external files, setting the reconstruction bounding box, and so forth. Since all of these tools are discussed at length in the online tutorials and in PhotoScan's user manual, I will elaborate just briefly on the main processing steps.

After loading the images into the software, in the initial 'Align Photos' step, PhotoScan first uses a so-called 'feature detection algorithm' to automatically identify and match features in overlapping pictures. Using these matching features, the software then runs a 'camera auto-calibration algorithm' to calculate the intrinsic camera parameters of the camera with which the pictures were taken. Next, based on the detected features and the camera calibration parameters, PhotoScan aligns the pictures relevant to one another through a process called 'feature-based alignment'. Feature-based alignment builds on the principle of intersecting rays; essentially, using at least three pictures with a matching feature point, a ray is projected from the focal point of each picture, through the detected feature points. The place where these rays intersect then determines the 3D coordinate of that feature point. The camera positions are identified by calculating the best fit for various rays projected from different cameras. When the process is repeated for all feature points in the dataset, the result is a sparse point cloud which is a $3 \mathrm{D}$ approximation of the scene in the pictures (Semyonov, 2011).

Since at this point both the original camera positions and the camera's calibration are known, the software can calculate precisely which pictures overlap where. Within this much smaller 'search area', in the 'Build Dense Cloud' step, PhotoScan again searches for matching features across pictures, but this time using a more computationally-intensive algorithm. If additional matching points are detected in at least three images, they can again be inserted into the $3 \mathrm{D}$ model using the principle of intersecting rays. If a feature point is detected in just two images, PhotoScan can still plot its 3D coordinates - in this case using the principle of parallax - though coordinates calculated from three overlapping images are generally more accurate. Once all of these additional feature points are added to the existing sparse point cloud, the result is a much more detailed dense point cloud (Semyonov, 2011).

Next, in the 'Build Mesh' step, PhotoScan creates a surface mesh from the dense point cloud. In the final 'Build Texture' step PhotoScan then 'projects' parts of the original pictures onto their corresponding points in the surface mesh and blends these source photos in order to generate a texture atlas for the model. The result is a final textured mesh which contains not only the geometric shape of the object of study, but also every colour, tone or texture detail visible in the original pictures (Semyonov, 2011).

While various other photogrammetry applications follow a very similar workflow, after initial experiments with a number of different software packages, PhotoScan stood out for a number of reasons. First of all, PhotoScan was simply the most reliable program I tested: whereas large image sequences or images of geometrically complex objects often failed to align or aligned incorrectly in other software applications, they generally aligned without much trouble in PhotoScan. Secondly, a lot of applications only perform part of the photogrammetry workflow described above, meaning users have to work with one program to perform initial picture alignment and then use another program to for instance generate the dense point cloud or mesh. By contrast, PhotoScan conveniently combines all processing steps from camera calibration to textured mesh generation in a single software package. Furthermore, unlike some so-called 'black box' applications, in PhotoScan the user retains full control over each of these different processing steps, meaning the photogrammetry procedure can be optimised and adapted to a wide range of different recording needs and scenarios. Finally, for someone like me, without a specialised technical or IT background, PhotoScan turned out to be surprisingly easy to use. As mentioned above, the software follows a very straightforward workflow, and every possible aspect of this workflow is covered by a wide range of online tutorials which target both beginners and advanced users.

Aside from these personal experiments, PhotoScan has generally also received positive reviews in scientific articles which compare various photogrammetry software applications to one another (Remondino et al., 2014, 2013, 2012; Sona et al., 2014). As such, while other programs might cost slightly less, in my experience PhotoScan is well worth the investment in order to avoid the hurdles and frustrations of working with cheaper, less powerful software packages. 


\section{TOWARDS A COMMON TERMINOLOGY}

The 'type' of photogrammetry discussed in this paper has been referred to under various names, including Multi-Image Photogrammetry, Close-Range Photogrammetry or Structurefrom-Motion Photogrammetry. A discussion between the author, Kotaro Yamafune, Massimiliano Ditta, Massimiliano Secci, Bruno Parés, Kevin Edwards and Rodrigo De Oliviera Torres - all of whom work in this specific domain - has highlighted the importance of using a common designation. Names such as Close-Range or Multi-Image Photogrammetry are ambiguous, simply because earlier photogrammetry approaches were also capable of processing multiple images, or images taken at close range. Structure-from-Motion Photogrammetry makes reference to a specific method commonly used to automatically generate a 3D point cloud from images, but the name leaves no room for other, often complementary approaches. As such, for the reasons discussed below, we believe the term 'Computer Vision Photogrammetry' best describes the type of photogrammetry referred to in this article.

Traditionally, the history of photogrammetry can be divided into several phases, based on the prevalent processing procedures used at different points in time. A commonly used classification is the one proposed by Gottfried Konecny, who differentiates between Plane Table Photogrammetry (theodolite survey aided by pictures), Analogue Stereo Photogrammetry (stereo pairs plotted using an analogue plotter), Analytical Photogrammetry (analogue pictures plotted using an analytical plotter, i.e. based on mathematics rather than on mechanics) and Digital Photogrammetry (digital rather than analogue pictures, plotted on a computer rather than on a plotter, using the same principles as Analytical Photogrammetry) (Konecny, 2010).

Each of these subsequent approaches to photogrammetry developed within the traditional field of photogrammetry itself - a field which was devoted almost exclusively to aerial mapping. In the 1960s a much younger, completely different field of study emerged, namely computer vision. At the time, researchers were optimistic about the prospect of creating intelligent machines; robots that could mimic human behaviour, that were capable of understanding and interacting with the world around them. Within this broader agenda of creating artificial intelligence, computer vision emerged as the field concerned with solving the 'visual input problem': developing methods which would allow machines to see and eventually perceive their surroundings. Researchers reasoned that if machines were going to understand their surroundings, they would first need to have an understanding of the 3D structure of those surroundings. Consequently, for several decades now the main objective of computer vision research has been 'to develop mathematical techniques for recovering the three-dimensional shape and appearance of objects in imagery' (Szeliski, 2010).

As such, all the techniques used in modern photogrammetry software - including automated feature detection, camera autocalibration, feature-based alignment, Structure-from-Motion, etc. - were developed not in the traditional field of photogrammetry, but in the field of computer vision. It is thanks to computer vision algorithms that applications such as PhotoScan can automatically detect points in overlapping pictures, in order to automatically calibrate our cameras, in order to automatically align images, in order to finally automatically generate a detailed 3D model. This unprecedented degree of automation provided by computer vision techniques is what truly sets the current generation of photogrammetry software apart from past approaches, and that is why we believe 'Computer Vision Photogrammetry' is the name which best describes this specific type of photogrammetry.

\section{CASE STUDY}

Typically underwater photogrammetry is easiest to perform on flat sites with ample natural lighting and good underwater visibility, based on pictures taken in a very structured manner using high-end pre-calibrated cameras. Rather than pursuing such 'ideal' conditions, in this case study I want to test what modern photogrammetry is capable of, by reconstructing a relatively large, complex three-dimensional site based on imagery captured in low-visibility conditions using widely available, low-cost cameras.

The data in question was obtained during the excavation of the Oostvoornse Meer 8, also known as the Straatvaarder wreck, by the underwater division of the Cultural Heritage Agency of the Netherlands in the summer of 2014. The wreck is located between 16 and $20 \mathrm{~m}$ depth, in what used to be an estuary leading from the North Sea, up the Brielse Maas to the city of Rotterdam. Dammed off from the North Sea in 1950, today the Oostvoornse Meer is a brackish water lake.

The site, which covers an area of approximately 15 by $8 \mathrm{~m}$, consists of the remains of a merchant vessel, built in the Dutchflush tradition. Dendrochronological dating of the ship timbers indicate the vessel was built in the second half of the $17^{\text {th }}$ century, and objects found on board suggest the ship sank in the first quarter of the $18^{\text {th }}$ century. Analyses of the vessel itself, and of associated personal artefacts, imply a Dutch provenance. Meanwhile a cargo of Spanish or Portuguese jars containing olive pits suggests the vessel was on its way back from the Mediterranean to Rotterdam when it sank (Kleij, 1993).

The Straatvaarder wreck was first professionally excavated and recorded in 1988 and 1989. As such, the purpose of the 2014 campaign was mainly to assess how the site's state of preservation had evolved since then, particularly taking into account the impact of teredo navalis (shipworm) on the wreck in recent years. The project also served as a field school for maritime archaeology students, and as an opportunity to experiment with a new recording method, in this case Computer Vision Photogrammetry.

During the campaign, over the course of four days, most of the vessel's remains were recorded, with the exception of the forward end of the hull, where only the ship's stempost protruded through the sediment. Photogrammetry was the primary recording method on the project, though as a backup the site was also recorded using offset drawings.

\subsection{Photogrammetry Recording Procedure}

Recording conditions varied considerably throughout the campaign: on day one visibility and natural lighting were good, but on days two to four the water turned murky and visibility was often no more than a metre, regularly falling below $50 \mathrm{~cm}$. In order to ensure sufficient image overlap in such low-visibility conditions, rather than using regular picture sequences, in this case photogrammetric modelling was done based on video footage. In particular, a GoPro HERO3 Black edition camera was used to capture the necessary data. 
Recording in low visibility meant filming very close to the wreck, in some cases as close as $20 \mathrm{~cm}$, in order to get images sharp enough for automated feature detection. Due to the relatively large extent of the site, this in turn meant a lot of footage had to be recorded in order to obtain full site coverage. In the murky conditions on days two to four, a single diffuse light was used to illuminate the otherwise dark wreck. To avoid backscatter, the light was mounted ca. $20 \mathrm{~cm}$ below the camera (Figure 1).

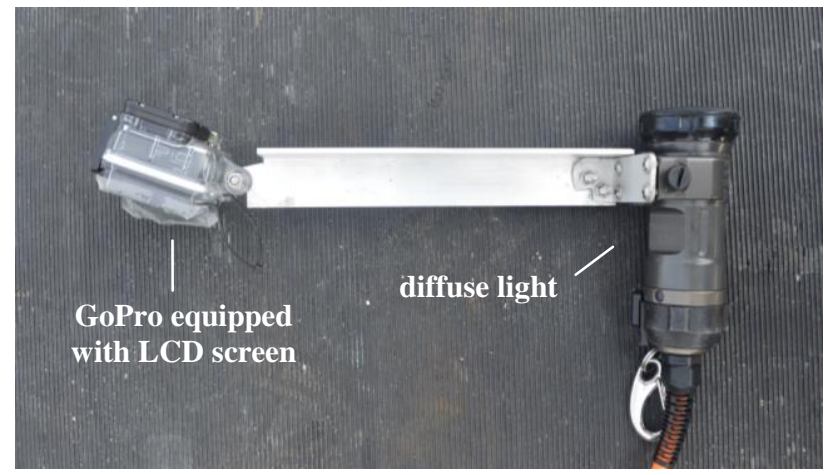

Figure 1. Basic camera setup used for recording

Before recording a certain area, the area was cleared of the bulk of sediment using an airlift. Directly prior to filming - in order to ensure that the remains were entirely clean - divers again made a brief pass over the area, wafting away any remaining sediment. When filming, participants were instructed to traverse the site in a lawnmower pattern, ensuring at least $60 \%$ overlap between consecutive lanes. During recording, an LCD screen mounted on the back of the GoPro allowed the divers to assess the data on the go, in order to ensure that each video was clear enough for photogrammetry purposes. To maintain a logistical overview of the data, each pass over the wreck was recorded as a separate video file. The upstanding stempost required a slightly different approach; in this case a diver swam in a slow spiral pattern around the post, recording the timber from base to top.

Back at the surface the captured data was then transferred to a laptop and the videos were catalogued according to date, diver and the part of the wreck recorded. Over the course of four days, during 15 individual dives, 181 short videos were recorded, for a total of 2:41 hours of video footage. The average length of each video was little over a minute, and typically during each 30 minute-dive about 11 minutes of video footage could be recorded. In the end ca. $40 \%$ of the total data, or 1:03 hours of video footage, was actually used for photogrammetric modelling. The remainder was either of insufficient quality for photogrammetry purposes, or redundant footage covering areas of the wreck already captured in other videos.

\subsection{Photogrammetry Processing Procedure}

Photogrammetry processing using the on-site laptop began as soon as the GoPros were back at the surface. After assessing video quality, frames from good videos were extracted using a software package called 'Free Video to JPG Converter'. In order to ensure sufficient image overlap between consecutive frames in the low-visibility environment, on average about 2 frames per second were extracted for each video. Several hundred frames from a number of consecutive lanes across the wreck site were then grouped into PhotoScan chunks and aligned using the 'low' accuracy setting. The 'low' accuracy setting was used because it allowed us to keep processing times to a minimum, and because experience had shown that the 'medium' and 'high' accuracy settings were more likely to cause misalignment issues, particularly on large image sequences.

A relatively high-end laptop equipped with an Intel Core i74700MQ (2.40GHz) processor, NVIDIA GeForce GTX 765M video card and 8GB RAM was used to process the data. With this setup, by leaving the software to run for the remainder of the day and throughout the night, by the next morning we usually knew whether all images in the chunk had aligned correctly. If not, alignment could be repeated using different settings until an adequate result was obtained or - in the worstcase scenario - the survey of a particular area could be repeated in order to obtain better footage.

Eventually a total of 7048 video frames (of which 6428 aligned successfully), were processed in 11 separate chunks, each chunk containing anywhere between 156 and 1571 images. After generating a dense point cloud, mesh and textured mesh for each chunk, the different chunks were aligned relative to one another by manually placing markers on easily recognisable points in the overlap between consecutive chunks, and then using PhotoScan's 'marker-based chunk alignment' function. Finally the chunks were merged into a single coherent model, a new texture map was generated for the site as a whole, and the model was scaled using known distances measured on the site.

The models of the 11 individual chunks were created over the course of five days during the campaign itself. Subsequent tidying up of the results, chunk alignment and final model generation were done over the course of another two days, after the campaign had ended. Since photogrammetry was the primary recording method on the Straatvaarder excavation, for the final publication the photogrammetry model (Figure 4) was also used as a basis to produce a lines plan (Figure 5), profile drawings, a digital elevation model (Figure 2) and an enhanced mesh (Figure 3 ) of the site. These additional representations were created in Adobe Illustrator, Quantum GIS and MeshLab respectively.

\subsection{Discussion}

The Straatvaarder case study illustrates that today photogrammetry is a viable recording method even for the documentation of large, complex sites in a low visibility environment. Average recording distance from the wreck was $66 \mathrm{~cm}$, though in particularly poor visibility this could drop to as little as $20 \mathrm{~cm}$. Recording in limited visibility therefore meant processing a large number of close-up video frames. Whereas in the past the manual alignment of 6000+ images would have been unrealistic, thanks to computer vision algorithms, the procedure is now largely automated and therefore relatively fast. By dividing the images over several chunks the images could be processed overnight, allowing us to assess the quality of the 3D results while still in the field. This helped us ensure good coverage for every part of the site, in order to produce a coherent overall site model.

The case study also illustrates that photogrammetric modelling from video footage is a viable alternative to modelling from regular picture sequences. Taking a picture every couple of centimetres to ensure sufficient image overlap would have been very challenging, and as such video footage provided an easy alternative. Divers could simply film in straight lines, and only 


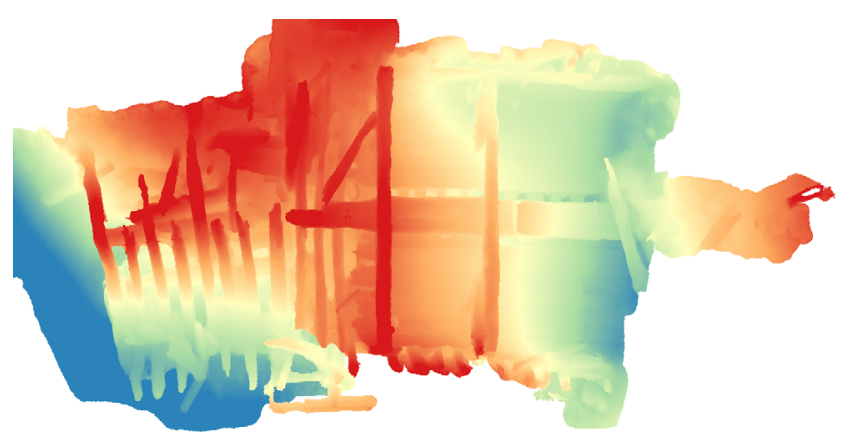

Figure 2. Digital elevation model of the Straatvaarder wreck, visualised in QuantumGIS

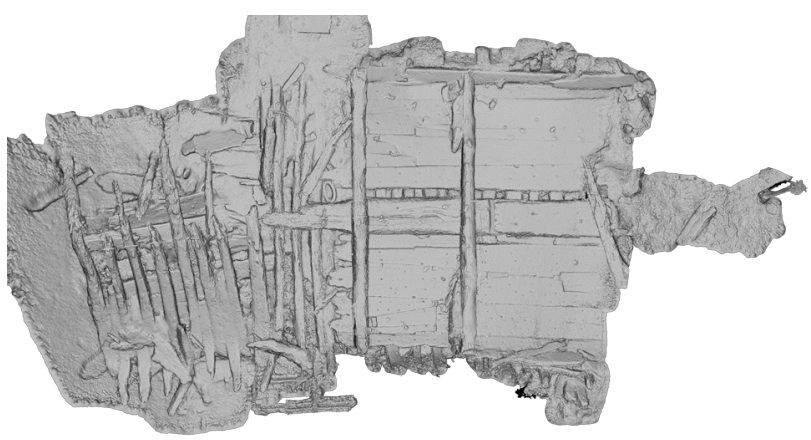

Figure 3. Surface mesh of the Straatvaarder wreck, enhanced using Radiance Scaling in Meshlab

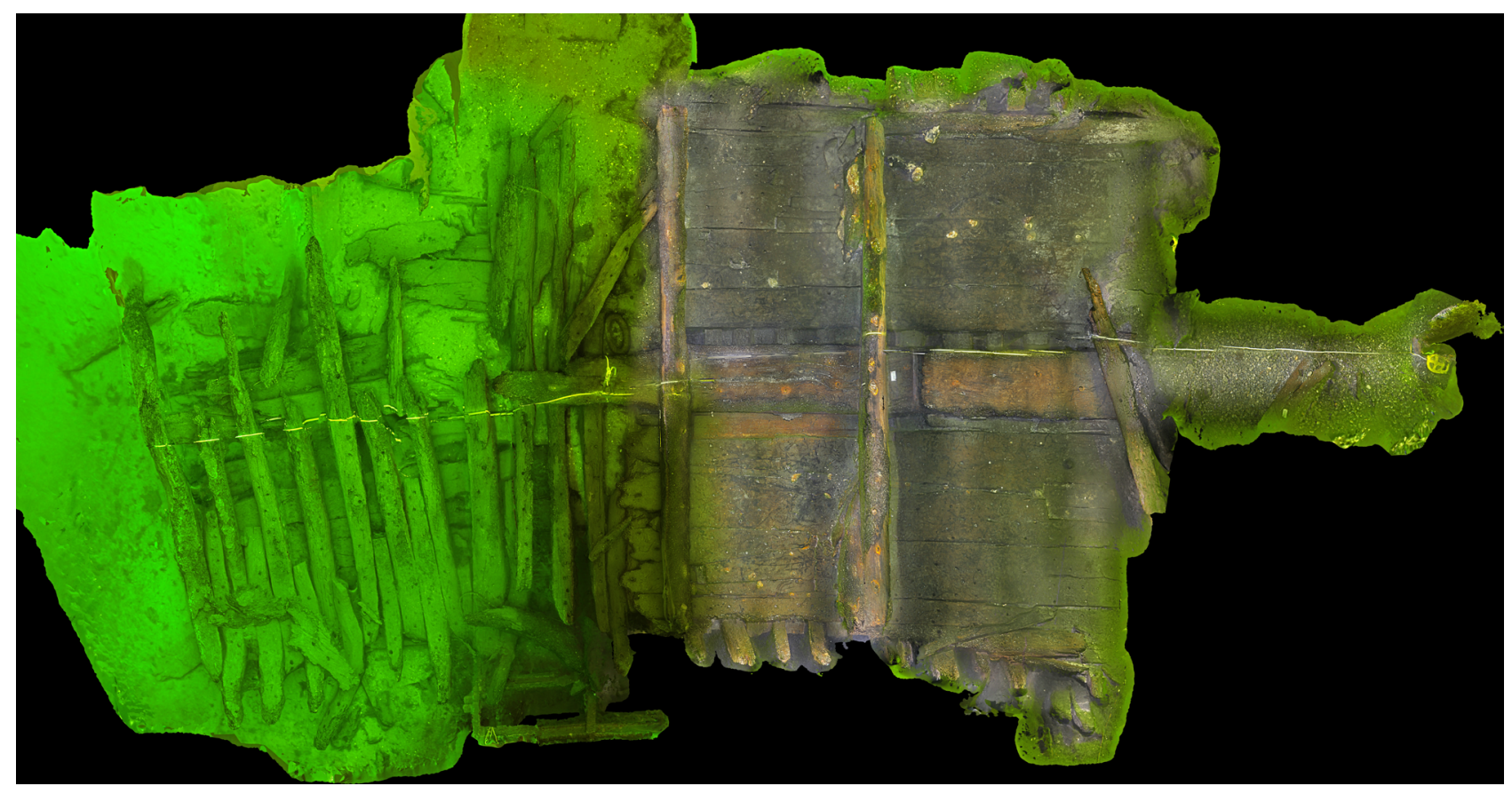

Figure 4. Orthophoto of the Straatvaarder wreck, produced in PhotoScan

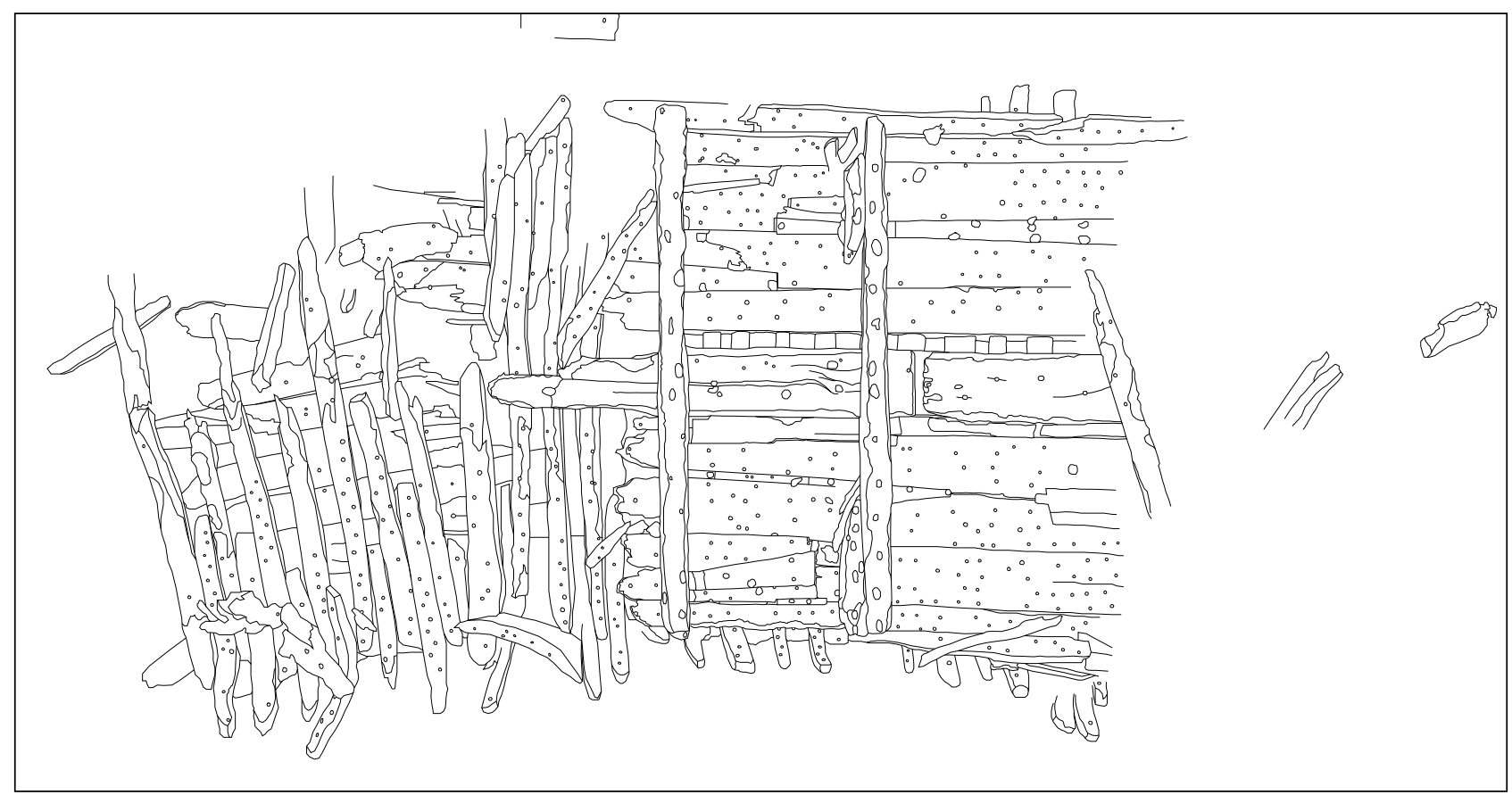

Figure 5. Lines plan of the Straatvaarder wreck, produced in Adobe Illustrator 
had to worry about ensuring enough overlap between consecutive lanes across the wreck, rather than having to worry about image overlap within each of these lanes.

Although the GoPro might have been an unusual choice for photogrammetric recording, in this case the camera's extreme wide-angle fisheye lens helped us keep the number of images to be processed - and therefore the processing times - to a minimum. Contrary to what one might expect, the perspective distortion caused by this type of lens did not present any issues during camera calibration. Although PhotoScan now has a specific setting for processing images taken with a fisheye lens, this setting was not required during processing; it seems that the perspective distortion caused by fisheye lenses is largely neutralized by the effects of underwater light refraction.

While each individual video frame was of relatively low resolution, by combining thousands of close-up images, the final model of the site is extremely detailed. As a result treenails, nail holes and in many cases even the grain of the wood, are clearly visible. As such it is important to stress that photogrammetry models are not just a nice tool for public dissemination - they also provide a highly accurate record of the site for scientific interpretation. In fact, the amount of information and detail contained in the final textured 3D model far surpasses anything we could have hoped to achieve using manual recording methods.

In terms of accuracy, based on known measurements performed on the site, PhotoScan calculates that the error margin within individual chunks is about $4 \mathrm{~mm}$; again much better than what could be expected from manual recording methods. Since we did not establish a network of ground control points, it is hard to assess the model's accuracy across these different chunks. Nevertheless, the simple fact that all 11 chunks fit together perfectly is already an indication that the model's overall accuracy is pretty high; simply put, if the chunks had contained large geometric deformations, they would never have puzzled together seamlessly like they did in this case study. As such, despite not being able to determine an absolute accuracy for the model as a whole, we can state with some confidence that the results are accurate enough for general archaeological purposes.

In terms of photogrammetry's efficiency compared to traditional recording methods, we should note that only three of the 20 divers involved in the campaign devoted some of their dives to photogrammetric recording. As I have mentioned above, these three divers only needed a total of 15 dives, or a combined 7:30 hours of dive time, to record the entire wreck site. This means that, had we devoted all of our attention exclusively to photogrammetry, several divers working simultaneously could have easily recorded the entire site in a single afternoon. By comparison, in order to create a backup plan of the site, over the course of four days, at any given time up to three people were simultaneously recording the site using manual offset drawings. As such it is clear that, despite the limited on-site visibility, photogrammetry was significantly more efficient than manual recording methods.

We can conclude that during this case study, compared to manual recording methods, Computer Vision Photogrammetry proved capable of significantly reducing underwater recording times, while simultaneously producing more detailed and presumably more accurate results. Furthermore, whereas offset drawings record only what the surveyor considers important at the time, Computer Vision Photogrammetry is a more objective recording method, since it indiscriminately documents every detail visible in the original pictures. Finally, whereas drawings are necessarily a two-dimensional simplification of a complex three-dimensional site, photogrammetry is capable of recording underwater sites in their full three dimensional intricacy.

Overall photogrammetry therefore produced a more complete and consequently more 'scientific' record of the Straatvaarder wreck, allowing for a more informed interpretation of the archaeological remains in the present, as well as a more comprehensive reassessment and scrutiny of the results in the future.

\section{THE SIGNIFICANCE OF CURRENT DEVELOPMENTS: A HISTORICAL PERSPECTIVE}

The Straatvaarder case study contributes to a growing body of research demonstrating the potential of Computer Vision Photogrammetry for underwater archaeological site recording. Nevertheless the question remains how significant these current developments in Computer Vision Photogrammetry are within the broader history of underwater recording. After all, as many readers are aware, Analytical and later Digital Photogrammetry have in fact been successfully used to document underwater archaeological sites since the 1960s, when photogrammetry was first used to create a site plan of the Roman shipwreck at Yassi Ada (Rosencrantz, 1975). If photogrammetry has been used in our discipline for so long, what is the point of discussing it again today? In order to answer this question, I first wanted to gain a better understanding of the overall 'impact' of photogrammetry in our discipline over time.

For this purpose, I conducted a bibliometric analysis of the use of the term 'photogrammetry' in publications on maritime archaeology over the past 55 years. After assessing several publication databases, Google Scholar turned out to provide the most complete record. In Google Scholar I therefore searched for publications containing the words 'photogrammetry' AND 'maritime archaeology' OR 'underwater archaeology' OR 'marine archaeology' OR 'nautical archaeology'. Publications mentioning photogrammetry were then assessed as a percentage of the total number of publications in our discipline over time. The results are shown in Figure 6.

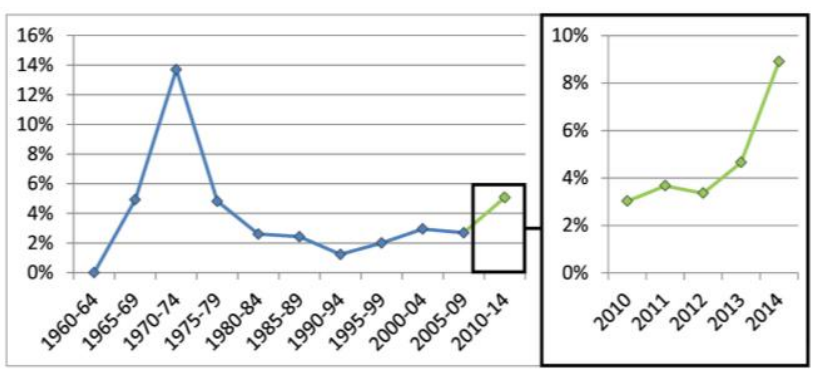

Figure 6. Use of the term 'photogrammetry' in publications on underwater archaeology over the past 55 years

Naturally this approach suffers from certain limitations, such as the fact that it does not take into account the significant contributions made by Scandinavian, German, French, Spanish, etc. researchers who published in their own languages. Nonetheless, the results are based on data from over 14000 underwater archaeology publications, and as such I believe they are statistically representative of photogrammetry's overall 'popularity' in our discipline over time. 
We can observe that after the initial optimism of the late 1960s - the results of which were typically published in the 1970s photogrammetry steadily received less and less attention, reaching an all-time low in the early 1990s. In the late 1990searly 2000s, thanks to Digital Photogrammetry applications such as PhotoModeler, photogrammetry regained a bit of popularity, though publications mentioning photogrammetry never exceeded $3 \%$ of the total corpus of maritime archaeology literature. As such, even though researchers were conscious of the various benefits of using photogrammetry, it seems projects actually using this recording method only ever represented a small fraction of all underwater archaeological research.

A thorough assessment of past publications on underwater photogrammetry suggests that this due to a number of interacting factors (Baker and Green, 1976; Baker and Henderson, 1979; Drap et al., 2006; Green et al., 2002; Leatherdale and Turner, 1988; Rosencrantz, 1975; to name but a few). Firstly, the hardware required to perform photogrammetry, such as dedicated plotting devices and precalibrated cameras, was expensive. Secondly the procedure of extracting useful metric information from pictures was very technical, meaning archaeologists generally had to rely on photogrammetry specialists for image processing. Furthermore pictures had to be taken in a very controlled manner in order to produce good photogrammetry results. This meant that a lot of planning went into each photogrammetric survey, and that the method was not very flexible or for that matter reliable. Finally, whereas underwater recording was very fast compared to manual recording methods, post-processing was typically slow and tedious since each image had to be aligned manually, and every single point of interest then had to be painstakingly identified in at least two overlapping pictures before its coordinates could be plotted. This proved particularly problematic in situations where a lot of pictures had to be aligned, such as on very shallow sites or on sites with limited visibility.

In short, despite producing possibly excellent results, for most archaeological projects the benefits of using photogrammetry could not outweigh the disadvantages, such as the risk of failed processing and the method's steep costs in terms of equipment, logistics and processing times, as well as the cost of hiring or training qualified personnel. As a result, for the most part the use of photogrammetry in underwater archaeology remained limited to a relatively small number of well-funded research projects where three-dimensional information was deemed very important, or to sites located at great depths, where manual recording was simply not a realistic option.

Today Computer Vision Photogrammetry software effectively overcomes all of the issues described above. Using software such as PhotoScan, the only hardware required to produce accurate photogrammetry models are a basic underwater camera and a decent personal computer, both of which already form part of most archaeologists' toolkit. Thanks to computer vision algorithms the whole photogrammetry process from camera calibration to feature detection, image alignment and model generation is performed more or less automatically. As a result archaeologists no longer have to rely on photogrammetry specialists for image processing. This new level of automation also means that thousands of images can now be aligned in a matter of hours, and rather than plotting just a small number of manually selected features, today computer vision algorithms can determine the 3D coordinates of millions of feature points in a matter of minutes. Finally Computer Vision
Photogrammetry is also increasingly capable of dealing with 'less-than-ideal' image sequences, such as the low-visibility fisheye video footage used in the Straatvaarder case study.

The overall result is that today, using Computer Vision Photogrammetry software such as PhotoScan, photogrammetry is easier to use, more flexible, more reliable and more affordable than ever before, while at the same time producing more accurate and more complete results than those attainable at any time in the past.

It is clear that other researchers are reaching similar conclusions (Figure 6). Over the past five years, with the advent of increasingly powerful and accessible Computer Vision Photogrammetry software, the number of references to photogrammetry in our discipline has increased exponentially. Furthermore, if we assess the past five years separately, it is clear that the term 'photogrammetry' really 'sky-rocketed' in 2014, when publications using the word represented nearly $9 \%$ of all maritime archaeology literature.

As such - thanks to the confluence of reduced costs and improved results - I believe that a certain 'tipping point' has finally been reached: for the first time, the performance of photogrammetry (in terms of recording and processing speeds, flexibility and quality of the 3D results) outweighs the costs (in terms of equipment, logistics, risk, and time and expertise required) not just for very well-funded projects, or projects where manual recording isn't an option, but on any archaeological site, given there is a minimum of underwater visibility. In fact, software applications such as PhotoScan leapfrog past obstacles faced in underwater photogrammetry so effectively, that in many underwater recording scenarios, the cost of using photogrammetry will now actually be lower than the cost of using manual recording methods; by cutting recording time to a fraction, the duration of archaeological projects can be significantly reduced, thereby avoiding many of the expenses involved in running a lengthy fieldwork campaign.

\section{CONCLUSION}

The Straatvaarder case study is just one among a rapidly growing number of case studies - published both in scientific journals and, more commonly, online - which demonstrate modern photogrammetry's potential for producing highly accurate, detailed 3D models of underwater sites using relatively simple underwater cameras and widely available software. Given the excellent results achieved in these case studies, and given the ease of use, affordability and reliability of modern photogrammetry procedures, we have every reason to believe that Computer Vision Photogrammetry will play an increasingly prominent role in the field of underwater archaeology in the years to come.

Now that the method's overall 'viability' has been broadly demonstrated, research focus is shifting to other interesting issues that merit further attention. These include questions related to how photogrammetry can influence and hopefully improve the way we conduct research, how this new technology can best be used to inform and engage the general public, and how we can best preserve this vast amount of digital data for future generations. Whatever the focus of such research, it is clear that many exciting future prospects still lie ahead. 


\section{ACKNOWLEDGEMENTS}

The present research was conducted in the context of my Master's thesis, and as such this article would not have been possible without the guidance of my thesis supervisor Jens Auer. I am similarly indebted to all members of the fantastic underwater archaeology team at the 'Rijksdienst voor het Cultureel Erfgoed', in particular to Johan Opdebeeck and Martijn Manders, for granting me the opportunity to participate on the Oostvoornse Meer excavations. Special thanks go to Morrison van der Linden and Sven Van Haelst for helping me collect the video footage used to model the Straatvaarder wreck. Throughout my research, the team at Agisoft - and most especially Alexey Pasumansky and Dmitry Semyonov - has gone above and beyond what can be described as 'good customer service', invariably providing excellent technical assistance and advice. Similar thanks go to the countless helpful PhotoScan Forum users, including Wishgranter and BigBen, for sharing their tips and tricks. Finally I would like to thank my fellow administrators at the 'Photogrammetry for Underwater Archaeology' Facebook group, namely Kotaro Yamafune, Massimiliano Ditta, Massimiliano Secci, Bruno Parés, Kevin Edwards and Rodrigo De Oliviera Torres, for their invaluable input over the course of numerous stimulating discussions.

\section{REFERENCES}

Agisoft LLC, 2014. Agisoft PhotoScan User Manual: Professional Edition, Version 1.1.

Baker, P.E., Green, J.N., 1976. Recording techniques used during the excavation of the Batavia. Int. J. Naut. Archaeol. 5, 143-158. doi:10.1111/j.1095-9270.1976.tb00952.x

Baker, P., Henderson, G., 1979. James Matthews excavation: A second interim report. Int. J. Naut. Archaeol. 8, 225-244. doi:10.1111/j.1095-9270.1979.tb01121.x

Drap, P., Seinturier, J., Scaradozzi, D., Gambogi, P., Long, L., Gauch, F., 2006. Photogrammetry for virtual exploration of underwater archaeological sites. Presented at the XXI International CIPA Symposium, Athens, pp. 1-6.

Green, J., Matthews, S., Turanli, T., 2002. Underwater archaeological surveying using PhotoModeler, VirtualMapper: different applications for different problems. Int. J. Naut. Archaeol. 31, 283-292. doi:10.1006/ijna.2002.1041

Kleij, P., 1993. Oostvoornsemeer Zuidoever: Een Straatvaarder voor Rotterdam, in: Reinders, R., van Holk, A. (Eds.), Scheepslading. Groningen, pp. 44-55.

Konecny, G., 2010. Geoinformation: Remote Sensing, Photogrammetry and Geographic Information Systems. Taylor \& Francis, London / New York.

Leatherdale, J., Turner, J., 1988. Commercial Underwater Photogrammetry - the First Decade.

Mahiddine, A., Seinturier, J., Boi, D.P.J., Drap, P., Merad, D., Luc Long, 2012. Underwater image preprocessing for automated photogrammetry in high turbidity water: An application on the Arles-Rhone XIII roman wreck in the Rhodano river, France. Presented at the 18th International Conference on Virtual Systems and Multimedia, pp. 189-194. doi:10.1109/VSMM.2012.6365924
Mahon, I., Pizarro, O., Johnson-Roberson, M., Friedman, A., Williams, S.B., Henderson, J.C., 2011. Reconstructing pavlopetri: Mapping the world's oldest submerged town using stereo-vision. Presented at the International Conference on Robotics and Automation, pp. 2315-2321. doi:10.1109/ICRA.2011.5980536

McCarthy, J., Benjamin, J., 2014. Multi-image Photogrammetry for Underwater Archaeological Site Recording: An Accessible, Diver-Based Approach. J. Marit. Archaeol. 9, 95-114. doi:10.1007/s11457-014-9127-7

Mertes, J., Thomsen, T., Gulley, J., 2014. Evaluation of Structure from Motion Software to Create 3D Models of Late Nineteenth Century Great Lakes Shipwrecks Using Archived Diver-Acquired Video Surveys. J. Marit. Archaeol. 9, 173-189. doi:10.1007/s11457-014-9132-x

Remondino, F., Del Pizzo, S., Kersten, T.P., Troisi, S., 2012. Low-Cost and Open-Source Solutions for Automated Image Orientation - A Critical Overview, in: Ioannides, M., Fritsch, D., Leissner, J., Davies, R., Remondino, F., Caffo, R. (Eds.), Progress in Cultural Heritage Preservation, Lecture Notes in Computer Science. Springer Berlin Heidelberg, pp. 40-54.

Remondino, F., Nocerino, E., Menna, F., Nex, F., Spera, M.G., Gonizzi-Barsanti, S., 2013. Dense image matching: comparisons and analyses. Presented at the Digital Heritage International Congress, The Eurographics Association, pp. $47-$ 54.

Remondino, F., Spera, M.G., Nocerino, E., Menna, F., Nex, F., 2014. State of the art in high density image matching. Photogramm. Rec. 29, 144-166. doi:10.1111/phor.12063

Rosencrantz, D.M., 1975. Underwater Photography and Photogrammetry, in: Photography in Archaeological Research, School of American Research Advanced Seminar Series. University of New Mexico Press, Albuquerque, pp. 265-309.

Semyonov, D., 2011. Algorithms used in PhotoScan [WWW Document]. Agisoft Community Forum. URL http://www.agisoft.com/forum/index.php?topic=89.0 (accessed 3.15.15).

Skarlatos, D., Demestiha, S., Kiparissi, S., 2012. An “open" method for 3D modelling and mapping in underwater archaeological sites. Int. J. Herit. Digit. Era 1, 1-24.

Sona, G., Pinto, L., Pagliari, D., Passoni, D., Gini, R., 2014. Experimental analysis of different software packages for orientation and digital surface modelling from UAV images. Earth Sci. Inform. 7, 97-107. doi:10.1007/s12145-013-0142-2

Steffy, J.R., 1994. Wooden Ship Building and the Interpretation of Shipwrecks. Texas A\&M University Press, College Station.

Szeliski, R., 2010. Computer Vision: Algorithms and Applications, 1st ed. Springer-Verlag New York, Inc., New York, NY, USA.

Zhukovsky, M.O., Kuznetsov, S.V., Olkhovsky, S.V., 2013. Photogrammetric Techniques for 3-D Underwater Record of the Antique Time Ship from Phanagoria. Remote Sens. Spat. Inf. Sci., International Archives of the Photogrammetry XL-5/W2, 717-721. 